\title{
Rapid diagnosis of whooping cough using monoclonal antibody
}

\author{
P C BORELAND,* S H GILlESPIE, $\dagger$ L A E ASHWORTH $\ddagger$ From the Departments of Medical \\ Microbiology, ${ }^{*}$ Waveney Hospital, Ballymena, Ireland; $\uparrow$ Royal Victoria Hospital, Belfast; and $\ddagger$ Experimental \\ Pathology Laboratory, PHLS, Centre for Applied Microbiology and Research, Porton Down, Salisbury
}

SUMMARY A counterimmunoelectrophoresis (CIE) method for antigen detection using monoclonal antibody was assessed for its ability to aid in the rapid diagnosis of Bordetella pertussis in 59 patients. A positive diagnosis from a combination of results from tests of serum and urine was obtained in 51 $(87 \%)$ of cases. For sera, CIE had a sensitivity of $85 \%$ and a specificity of $94 \%$; for urine samples the sensitivity was $81 \%$ and a specificity of $100 \%$. Antigen detection by CIE is simple to perform and yields results on the same day, thus allowing treatment to begin at an early stage.

Bordetella pertussis is responsible for an acute respiratory tract infection in children. This highly infectious disease has not been controlled fully by vaccination, partly due to the incomplete protection afforded by the vaccine and poor vaccination rates due to fears of possible toxicity. As a result the community continues to be subject to epidemics of whooping cough when the number of reported cases may exceed 1000 per week.' The very young are particularly susceptible with several deaths each year. ${ }^{2}$

Precise diagnosis is needed to prevent unnecessary or inappropriate treatment with antibiotics, and to alleviate parental anxiety. If antimicrobial agents are to be effective in changing the course of the disease they must be given as early as possible, preferably during the catarrhal stage. ${ }^{3}$ At this stage, however, symptoms and signs are non-specific, resembling the many other respiratory infections common in this age group. ${ }^{4}$

A counterimmunoelectrophoresis (CIE) method for antigen detection using polyclonal antibody providing the opportunity for rapid diagnosis has previously been described. ${ }^{5}$ This study reports the use of a monoclonal antibody in a CIE system for the detection of $B$ pertussis antigen.

\section{Material and methods}

Fifty nine patients who had been admitted to the Northern Ireland Fever Clinic, Belvoir Park Hospital with suspected whooping cough were recruited to the study. The diagnosis was made on the clinical history and the presence of a characteristic cough. The presence of an absolute lymphocytosis was used to support the diagnosis. A total of 55 children were confirmed as suffering from whooping cough. Twenty four were male and 35 female; 11 were under 3 months Accepted for publication 25 November 1987 of age, 11 between 3 and 6 months, a further five were under 1 year, and the remainder were under 6 years of age. Pernasal swabs were obtained, together with serum and urine samples wherever possible. An age and sex matched control group was established from whom serum and urine samples were taken from routine paediatric admissions to the Waveney Hospital, Ballymena, Northern Ireland.

Pernasal swabs were transported to the laboratory with minimal delay, inoculated onto Lacey's modification of Bordet Gengou agar, and incubated aerobically for five days. Samples of serum and urine were stored at $-20^{\circ} \mathrm{C}$ until examined by CIE.

The hybridoma clone Ag51/10 arose from a hybridisation procedure designed to yield monoclonal antibodies to pertussis serotype agglutinogens. ${ }^{6} \mathrm{Balb} / \mathrm{c}$ mice were inoculated with $B$ pertussis fimbriae prepared from Wellcome strain 28 cells by potassium thiocyanate extraction and gel filtration on Sepharose 6B. ' Two mice received about $30 \mu \mathrm{g}$ of antigen in Freund's complete adjuvent distributed between a number of intramuscular and subcutaneous sites. Seven weeks later they were given $25 \mu$ g intravenously/ intraperitoneally without adjuvant. A final $25 \mu \mathrm{g}$ was given intravenously six days later and the spleens taken after a further four days. Techniques of fusion were as described previously. ${ }^{8}$ Hybridoma supernatants were screened by microagglutination of $B$ pertussis cells. Antibody Ag51/10 was an IgG antibody which agglutinated a variety of serotypes and was shown to have specificity for lipopolysaccharide (LPS) by double diffusion $v$ phenol/water purified LPS (LI Irons, personal communication). It was the only one of a number of antibodies to $B$ pertussis which yielded a precipitin line in the CIE system described below.

CIE was carried out on $0.75 \%$ agarose (Uniscience)

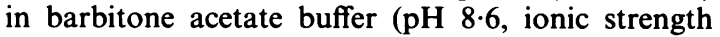


Table Results of CIE for B pertussis antigen compared with those of conventional culture

\begin{tabular}{lccccc}
\hline & Urine & Urine* & Serum & Serum & Pernasal swab \\
\hline Clinical & $26 / 32$ & $10 / 28$ & $28 / 40$ & $9 / 15$ & $27 / 54$ \\
Respiratory illness, not whooping cough & $0 / 4$ & 0 & $1 / 4$ & $0 / 3$ & 0 \\
Controls & $0 / 14$ & $0 / 14$ & $0 / 14$ & $0 / 14$ & Not done \\
\hline
\end{tabular}

*Concentrated specimen.

$0.05 \mathrm{M}$ ) on glass slides $8 \mathrm{~cm} \times 10 \mathrm{~cm}$. Wells $2.5 \mathrm{~mm}$ in diameter were cut in parallel rows $2 \mathrm{~mm}$ apart; $6 \mu / 1$ of either serum or urine was placed in wells on the cathode side of the plate and monoclonal antibody, and $6 \mu / 1$ in the form of ascitic fluid was added to the wells nearest the anode. Pertussis vaccine was used as a positive control.

After electrophoresis at a constant current of $20 \mathrm{~mA}$ for 30 minutes the plate was examined for the presence of precipitin lines using a $\times 8$ hand lens and dark ground illumination. The plate was re-examined after storage at $4^{\circ} \mathrm{C}$ for 30 minutes and again after 24 hours. Where there was sufficient material all negative specimens were concentrated (serum $\times 5$ and urine $\times 50$ ) using Minicon concentrators (Amicon) and the CIE repeated. The sensitivity and specificity of CIE and conventional culture methods and the predictive value of a positive and negative result were calculated according to the formulae of Galen and Gambino. ${ }^{9}$

\section{Results}

Pernasal culture was positive for B pertussis in $50 \%$ of cases and an absolute lymphocytosis in $89 \%$. A positive diagnosis using CIE from a combination of results from tests of serum and urine was obtained in $87 \%$ of cases. Urine proved to be the most positive specimen with urines from $81 \%$ of cases having detectable antigen compared with $70 \%$ of sera. Concentration of the specimen resulted in a decrease in the number of positive results from 26 of 32 to 10 of 28 . This may have been due to absorption of the lipopolysaccharide antigen to the concentrator membrane. A smaller fall occurred in serum specimens (table).

Among the four children in whom a diagnosis of whooping cough was not confirmed clinically was one positive result from a serum sample. This child had measles and a concomitant infection with $B$ pertussis could not be excluded. Fourteen paediatric patients from the Waveney Hospital with other respiratory illness all had negative readings.

Culture of pernasal swabs on Lacy's modification of Bordet-Gengou had a sensitivity of $50 \%$ and a specificity of $100 \%$. For sera, CIE had a sensitivity of $85 \%$ and a specificity of $94 \%$. The predictive value of a positive result is $85 \%$ and a negative result $75 \%$. CIE of urine samples gave a sensitivity of $81 \%$ and a specificity of $100 \%$. The predictive value of positive and negative tests was $100 \%$ and $75 \%$, respectively.

The sera of four strongly positive patients were absorbed with monoclonal antibody and on subsequent testing were shown to be negative.

\section{Discussion}

The method for antigen detection by CIE reported here is simple to perform and yields results on the same day. In a previous study CIE was shown to be of particular value in the diagnosis of patients who had been coughing for less than two weeks. ${ }^{5} \mathrm{CIE}$ for $B$ pertussis LPS was similarly able to detect antigen relatively early in the clinical course, with a positive diagnosis made in $66 \%$ of children whose parents gave a history of coughing for less than two weeks, and in about $80 \%$ of children who had been coughing for more than two weeks. The test therefore has the potential for rapid diagnosis which would allow treatment to begin at an early stage.

CIE has gained a place in the rapid diagnosis of many bacterial infections. Methods have been described that detect the capsular polysaccharide of Neisseria meningitidis and Haemophilus influenza. ${ }^{10}$ Similarly, the detection of flagellar Vi and LPS antigen is under investigation in the diagnosis of enteric fever."

Laboratory diagnosis of whooping cough by bacterial isolation is difficult as Bordetella pertussis combines fastidious growth requirements, rapid death in transport ${ }^{12}$ with a tissue tropism which ensures that specimens are contaminated with faster growing organisms. Under optimal conditions a positive culture is obtained in $10-40 \%$ of clinically typical cases. ${ }^{13}$

Although detection of organisms in pernasal swabs by immunofluorescence is sometimes accomplished, much of the effort in the diagnosis of pertussis is directed toward the detection of specific antibody. Techniques that have been used include haemagglutination, direct agglutination, and complement fixation. ${ }^{1214-17}$ Several ELISA techniques have also been described with varying results. $B$ pertussis specific IgG, IgA, and IgM have been measured in serum from children and adults using sonicated $B$ pertussis as antigen. ${ }^{18}$ Thirty five of these cases (of 47) with 
suspected whooping cough were diagnosed on a first serum sample. The authors emphasise the difficulties of antibody tests in children under 6 months, recommending paired sera. Using filamentous haemaglutinin as antigen, positive titres of IgM or high titres of IgG antibody in the first serum sample were found in only 26 of the 49 patients tested. An $82 \%$ rapid diagnosis was claimed using a combination of culture and serology. ${ }^{19}$

This method clearly improves the speed of diagnosis but its poor sensitivity on a single sample and dependence on multiple assays means that it is not truly rapid. The usefulness of serum antibody detection in whooping cough will be limited by the time taken for the immune response to develop. ${ }^{120}$ The retrospective diagnosis provided is therefore most useful in epidemiological studies.

A further problem with serum antibody techniques stems from the difficulty in obtaining blood routinely, particularly from children under 6 months who are most at risk from the complications of whooping cough. Although this is rarely a problem in hospital practice, few general practitioners will perform venipuncture on such young children. Whooping cough is predominantly managed in the community and diagnosis from a urine sample would therefore be ideal. Detection of urinary antigen, readily accomplished in this study, could be made widely available to general practitioners, preventing unnecessary antibiotic treatment or hospital admission.

We thank Drs DA Canavan, FLJ Robinson, JG Jenkins, and $\mathrm{J}$ Lim for their help with patients and specimens, together with the nursing and laboratory staffs of the Northern Ireland Fever and Waveney Hospitals. We also thank Dr LI Irons for supplying the preparations used to immunise mice and $\mathrm{Dr} P$ Wilton-Smith for deriving the monoclonal producing cell lines.

\section{References}

1 The Office of Population Censuses and Surveys. Monitor MB2 87/1. London: HMSO, 1987:5.

2 Miller CL, Fletcher WB. Severity of notified whooping cough. $\mathrm{Br}$ Med J 1976;i:117-9.

3 Bass JW, Klenk EL, Krotheimer JB, Linneman CC, Smith MHD.
Antimicrobial treatment of pertussis. J Paediatr 1969;75: 768-81.

4 Christie AB. Infectious diseases: epidemiology and clinical practice. 3rd ed. Edinburgh: Churchill-Livingstone, 1981:659-82.

5 Boreland PC, Gillespie SH. Counterimmunoelectrophoresis in the diagnosis of whooping cough. J Clin Pathol 1984;37:950-1.

6 Ashworth LAE, Dowsett AB, Irons LI, Robinson A. The location of surface antigens of Bordetella pertussis by immunoelectron microscopy. Proceedings of the 4th International Symposium on pertussis. Devel Biol Standards 1985;61:143-51.

7 Irons LI, Ashworth LAE, Robinson A. Release and purification of fimbriae from Bordetella pertussis. Proceedings of the 4th International symposium on pertussis. Devel Biol Standards 1985;61:153-63.

8 Irons LI, Ashworth LAE, Wilton-Smith P. Heterogeneity of the filamentous haemagglutinin of Bordetella pertussis studied with monoclonal antibodies. J Gen Microbiol 1983;129:2769-78.

9 Galen RS, Gambino SR. Beyond normality: the predictive value and efficiency of medical diagnoses. London: John Wiley \& Sons, 1976.

10 Greenwood BM, Whittle HC, Dominic-Rajkowic O. Counter immunoelectrophoresis in the diagnosis of meningococcal infections. Lancet 1971;ii:519-21.

11 Gupta AK, Rao KM. Simultaneous detection of Salmonella typhi antigen and antibody in serum by counterimmuno electrophoresis for an early and rapid diagnosis of typhoid fever. $J$ Immunol Methods 1979;30:349-53.

12 Combined Scottish study. Diagnosis of whooping cough: comparison of serological tests with isolation of Bordetella pertussis. $\mathrm{Br}$ Med J 1970;4:637-9.

13 Walker E, Pinkerton JW, Love WC, Chaudri AKR, Datta JB. Whooping cough in Glasgow 1969-1980. J Infect 1981;3:150-8.

14 Abbot JD, Preston NW, MacKay RI. Agglutinin response to pertussis vaccination in the child. Br Med J 1971;i:86-8.

15 Macauley ME. The serological diagnosis of whooping cough. $J$ Hyg (Camb) 1979;83:95-102.

16 Winter JL. Development of antibodies in children convalescent from whooping cough. Proc Soc Exp Biol Med 1953;83:866-70.

17 Bradstreet CMP, Taunahill AJ, Edwards JMB. Detection of Bordetella pertussis antibodies in human sera by complement fixation and immunofluorescence. J Hyg (Camb) 1972;70: 75-83.

18 Mertsola J, Ruuskanen O, Kuronen T, Viljanen MK. Serologic diagnosis of pertussis: comparison of enzyme-linked immunosorbent assay and bacterial agglutination. J Infect Dis 1983;147:252-7.

19 Granstrom M, Granstrom G, Lindfors A, Askelof P. Serological diagnosis of whooping-cough by an enzyme-linked immunosorbent assay using fimbrial haemagglutinin as antigen. $J$ Infect $D i s$ 1982;146:741-5.

20 Nagel J, Poot-Scholtens EJ. Serum IgA antibody to Bordetella pertussis as an indicator of infection. J Med Microbiol 1983;16:417-26.

Requests for reprints to: Dr SH Gillespie, Department of Clinical Tropical Medicine, London School of Hygiene and Tropical Medicine, Keppel Street, London WC1E 7HT, England. 